Article

\title{
Synthesis of Silicon Hybrid Phenolic Resins with High Si-Content and Nanoscale Phase Separation Structure
}

\author{
Wenjie Yuan ${ }^{1,2}$, Fenghua Chen ${ }^{1, *}$ (i), Shan $\mathrm{Li}^{1}$, Youpei Du ${ }^{1,2}$, Zhenhua Luo ${ }^{1}$, Yanan Sun ${ }^{1,2}$, \\ Hao $\mathrm{Li}^{1, *}$ and Tong Zhao ${ }^{1,2, *}$ \\ 1 Key Laboratory of Science and Technology on High-tech Polymer Materials, Institute of Chemistry, \\ Chinese Academy of Sciences, Beijing 100190, China; yuanwenjie@iccas.ac.cn (W.Y.); \\ lishan@iccas.ac.cn (S.L.); duyoupei@iccas.ac.cn (Y.D.); z.h.luo@iccas.ac.cn (Z.L.); sunyanan@iccas.ac.cn (Y.S.) \\ 2 College of Chemistry and Chemical Engineering, University of Chinese Academy of Sciences, \\ Beijing 100049, China \\ * Correspondence: fhchen@iccas.ac.cn (F.C.); lihao306@iccas.ac.cn (H.L.); tzhao@iccas.ac.cn (T.Z.)
}

Received: 15 August 2020; Accepted: 2 September 2020; Published: 10 September 2020

check for updates

\begin{abstract}
In this paper, a set of silicon hybrid phenolic resins (SPF) with high Si-content were prepared by mixing phenolic resins with self-synthesized silicon resins. In order to obtain the nanoscale phase structure, condensation degree and the amount of Si-OH groups in silicon resins were controlled by the amount of inhibitor ethanol in the hydrolytic condensation polymerization of siloxane. Increasing the amount of ethanol resulted in more silanol groups and a lower degree of condensation for silicon resins, which then led to more formation of $\mathrm{Si}-\mathrm{O}-\mathrm{Ph}$ bonds in hybrid resin and improved compatibility between silicon resin and phenolic resin. When $400 \%$ ethanol by weight of siloxane was used in the sample SPF-4, nanoscale phase separation resulted. The residual weight of the cured SPF- 4 at $1000{ }^{\circ} \mathrm{C}$ $\left(R_{1000}\right)$ significantly increased compared to pure phenolic resins. The result of the oxyacetylene flame ablation and the Cone Calorimeter test confirmed the improved ablative property and flammability after the modification. The performance improvement of the cured SPF-4 was attributed to the nanoscale phase structure and high silicon content, which promoted the formation of dense silica protective layers during pyrolysis.
\end{abstract}

Keywords: silicon hybrid phenolic resin; nanoscale phase separation; oxidation resistance; ablative property

\section{Introduction}

Phenolic resins, a kind of classical thermosetting resins, are widely used as the matrix for ablative composites or a precursor for $\mathrm{C} / \mathrm{C}$ composites in the aerospace field owing to their excellent properties such as flame retardancy, low cost, high char yield, and high strength of pyrolysis products [1-3]. However, phenolic hydroxyls (Ph-OHs) are easily converted into hydroxyl radicals in the pyrolysis process due to the low bond dissociation energy of $\mathrm{O}-\mathrm{H}$ and $\mathrm{C}-\mathrm{O}$ bonds, as well as methylene groups can decompose into methyl groups. In addition, auto-oxidation occurs during thermal degradation, which seriously affects the anti-oxidation and thermal stability of cured phenolic resins and limits their application under the long-term high-temperature conditions [4-7]. Introducing other elements such as silicon, boron, and phosphorous is an effective approach to improve the oxidation resistance and ablative properties of phenolic resins [8-10] due to the oxides with high melt point formed by these elements can increase the residual weight of phenolic resins at high temperature.

In recent years, polysiloxane has attracted more attention because of its excellent properties [11]. The polysiloxane has main chain Si-O-Si and organic groups bonded to the silicon atom. Since a Si-O bond has higher bond energy $(443.7 \mathrm{KJ} / \mathrm{mol})$ and better molecular chain flexibility than a C-C bond 
$(347.4 \mathrm{KJ} / \mathrm{mol})$, the unique structure of the "semi-inorganic and semi-organic" endows polysiloxane outstanding thermal and chemical stability, flexibility, ablation property and flame retardancy [12-14], making polysiloxane widely used for heat-resistant and ablation coatings. However, due to the lower mechanical strength, polysiloxane is hardly used as a matrix resin of ablative composites [15].

Hybridization of polysiloxane with phenolic resin is an effective approach to improve the toughness and thermal properties of phenolic resins and increase the strength of polysiloxane [16,17]. Unfortunately, the large difference of solubility parameters between polysiloxanes (7.3 7.5) and phenolic resins (10.5 11.5) [18,19] resulted in poor compatibility between these two resins. When high molecular weight polysiloxane and/or high amount of polysiloxane were introduced into phenolic resins, macroscopic phase separation usually occurred in the cured hybrid resins, which resulted in decreased mechanical properties, low oxidation resistance, and poor ablative property [20].

In order to improve the performance of silicon-modified phenolic resin, a good deal of research has been devoted to enhancing compatibility between phenolic resins and polysiloxanes, including coupling agent introduction [21-24], chemical group grafting [25-28], copolymerization [29,30] and in situ polymerization $[9,10,16]$. K. Haraguchi [16] group prepared phenolic/silica hybrid resins by in situ polymerizations of silicon alkoxide in phenolic resins. They found that the fine morphology of the cured hybrid resins was dependent on the relative rates of phase separation and crosslinking, with further phase separation leading to more aggregation of silica and microphase separation. This cured hybrid resins containing $12 \mathrm{wt} . \%$ of silica with $10 \sim 30 \mathrm{~nm}$ in size and little agglomerations of silica were observed. Lixin Chen et al. [10] added siloxane monomers at the final synthesis stage of phenolic resins to obtain the silicon-containing phenolic resins with improved thermal and mechanical properties. When the amount of siloxane added was $14 \mathrm{wt} . \%$, no clear phase separation phenomenon was observed in the hybrid resin through SEM observation.

With the demands of long-term ablation performance in aerospace applications, high content of anti-oxidant components such as polysiloxanes is expected for the hybrid phenolic resins. In order to avoid macroscopic phase separation, the interaction between polysiloxanes and phenolic resins should be tremendously increased. Li et al. [22] prepared a novel amphiphilic molecule (coupling agent) and conducted copolymerization to synthesize hybrid resin. A large amount of siloxane (more than $30 \mathrm{wt} . \%$ ) was introduced, and co-continuous phase structure with periodic length $(60 \mathrm{~nm})$ was formed in the cured hybrid resin. However, high-cost and complicated synthesis process and low thermal stability were not beneficial for the application of the coupling agent. As shown in Figure 1, by comparing phase separation length and silicon content of various silicon modified phenolic resins [16,20-22,31,32], it was found that fine phase structure and high silicon content are difficult to achieve at the same time. Therefore, a high-performance silicon-modified phenolic resin with high silicon content and fine phase morphology is expected to develop by simple and economical preparation methods.

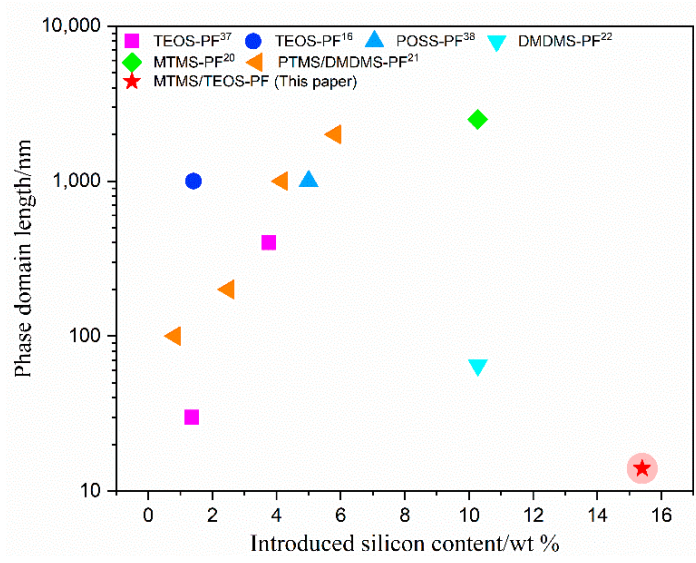

Figure 1. Phase domain length and introduced silicon content of reported silicon modified phenolic resins, with the relevant references shown at the upper right of each item. 
This paper aimed to prepare a silicon hybrid phenolic resin with a high Si-content, nanoscale phase separation structure, and lower cost in practice. Different molecular structures of silicon resins were synthesized by varying the hydrolysis-condensation of methyltrimethoxysilane (MTMS) and tetraethoxysilane (TEOS), then the hybrid resins were obtained by mixing silicon resins with phenolic resins. Silicon modified phenolic resins with nanoscale phase separation were prepared. The thermal property, oxidation resistance, ablative property, and flame retardancy of the cured hybrid resins with nanoscale phase structure were enhanced.

\section{Experimental}

\subsection{Materials}

Formaldehyde (37\%), acetic acid, ethyl alcohol, and barium hydroxide were obtained from Beijing Chemical Industries. Methyltrimethoxysilane (MTMS) was purchased from Hubei New Blue Co. Ltd., China. Tetraethoxysilane (TEOS) was obtained from Xilong Scientific Co. Ltd., China. Phenol was purchased from Sinopharm Chemical Reagent Co. Ltd., China. The short-chopped high silica glass fiber was supplied by Shaanxi Huatek Fiberglass Materials Group Co. Ltd. (Xingping, China).

\subsection{Preparation of Phenolic Resins (PF)}

Phenolic resins (resoles type) were prepared through a conventional route. Phenol ( $1 \mathrm{~mol})$, formaldehyde $(1.6 \mathrm{~mol})$ and barium hydroxide $(0.015 \mathrm{~mol})$ were added into $250 \mathrm{~mL}$ three-necked flask equipped with a stirrer, a cooling condenser, a thermometer. All reagents were gradually heated to $80^{\circ} \mathrm{C}$ for $30 \mathrm{~min}$ and $90^{\circ} \mathrm{C}$ for $2 \mathrm{~h}$. At the end of the reaction, water and by-products were distilled under reduced pressure at $90^{\circ} \mathrm{C}$, and then PF resin solution $(65 \mathrm{wt} . \%)$ was obtained by adding a certain amount of ethanol.

\subsection{Synthesis of Silicon Resins (SR)}

SR solution was synthesized by dissolving MTMS and TEOS (molar ratio of MTMS to TEOS being 1:4) into ethanol. The amount of ethanol was $100 \%, 200 \%, 400 \%$ by weight of siloxane, and the obtained silicon resins were designated as SR-1, SR-2, SR-4, respectively. SR-0 denoted the sample without ethanol added. Then distilled water (the molar ratio of water to alkoxy groups being 1:1) and a certain amount of acetic acid ( $5 \%$ by total weight) was added dropwise to initiate the hydrolysis of the alkoxy groups. SR solution was obtained through the hydrolysis-condensation of MTMS and TEOS at $30^{\circ} \mathrm{C}$ for $6 \mathrm{~h}$.

\subsection{Preparation of Hybrid Resins and Hybrid Composites}

The transparent yellow hybrid resins solution was prepared by mixing solution of PF and SR with a weight ratio of 1:1 (pure resin weight) with magnetic stirring for $2 \mathrm{~h}$ at room temperature, and hybrid resins obtained from SR-0, SR-1, SR-2, SR-4 were named as SPF-0, SPF-1, SPF-2, SPF-4, respectively. The resin solution was cured following the procedure $80^{\circ} \mathrm{C}(10 \mathrm{~h})+120^{\circ} \mathrm{C}(2 \mathrm{~h})+180^{\circ} \mathrm{C}(4 \mathrm{~h})$.

Preparations of the SPF- 4 and PF composites were as follows. The fiber was infiltrated in the resin solution, then placed in the fume hood for $10 \mathrm{~h}$ and put in the oven at $75^{\circ} \mathrm{C}$ for $30 \mathrm{~min}$. The mixture of chopped glass fiber with hybrid resins by weight ratio $6: 4$ was put in the mold and pressed on the hot plate under pressure of $30 \mathrm{~kg} \cdot \mathrm{cm}^{-2}$ at $120^{\circ} \mathrm{C}$ for $2 \mathrm{~h}$ and $180^{\circ} \mathrm{C}$ for $4 \mathrm{~h}$, and the laminated board was finally obtained.

\subsection{Characterization}

Fourier Transform Infrared Spectroscopy (FTIR) measurements were performed on a Tensor-27 spectrometer at room temperature. Samples were ground, mixed with $\mathrm{KBr}$ and pressed into small flakes for testing. ${ }^{1} \mathrm{H}-\mathrm{Nuclear}$ Magnetic Resonance (NMR) and ${ }^{29} \mathrm{Si}-\mathrm{NMR}$ spectra were recorded on an Avance III 400 HD NMR spectrometer. Gel Permeation Chromatography (GPC) was used to measure 
molecular weight and distribution of the silicon resins on Waters 1515 with tetrahydrofuran as the mobile phase. Thermogravimetric Analysis (TGA) was carried out from ambient temperature to $1000{ }^{\circ} \mathrm{C}$ on a Netzsch STA409PC at a heating rate of $10^{\circ} \mathrm{C} \cdot \mathrm{min}^{-1}$ in nitrogen and air atmospheres, respectively. The cured SPF resin samples were quenched and cracked in liquid nitrogen, and the fracture surface of the hybrids was observed on a Hitachi S-8020 Scanning Electron Microscope (SEM) at an accelerating voltage of $10 \mathrm{kV}$. Energy Dispersive X-ray spectroscopy (EDS) was Oxford INCAx-sight 7593 system attaching to the SEM apparatus. A high-temperature oxidation test was performed in a muffle furnace at the desired temperature for a different duration. Cone Calorimeter (CC) tests were performed on an FTT0007 device (UK) according to ISO 5660 with an incident flux of $50 \mathrm{~kW} \cdot \mathrm{m}^{-2}$. For each resin (composite), three specimens were tested. An oxyacetylene flame test was carried out to evaluate the mass ablative rate of the composite, according to GB323A-96. At least three specimens with a dimension of approximately $30 \mathrm{~mm}$ (diameter) $\times 10 \mathrm{~mm}$ (thickness) were prepared for each test, and the exposure time for each ablation test under the torch flame was $20 \mathrm{~s}$. The average value was obtained for each resin. Thermogravimetric Analysis Infrared (TG-IR) spectra were recorded using a TGA thermogravimetric analyzer that was interfaced to a Tensor-27 FTIR spectrophotometer. About $10.0 \mathrm{mg}$ sample was tested from 30 to $1000{ }^{\circ} \mathrm{C}$ at a heating rate of $10^{\circ} \mathrm{C} \cdot \mathrm{min}^{-1}$ under the air atmosphere. Brunauer-Emmett-Teller (BET) surface areas were measured by nitrogen adsorption by induced isotherms at $77 \mathrm{~K}$ with a Micromeritics ASAP 2020 instrument. Small-Angle X-ray Scattering (SAXS) experiments were carried out with the aid of a semiconductor detector (Pilatus 100K, DECTRIS, Dättwil, Switzerland) attached to a conventional Ni-altered Cu Ka X-ray source (GeniX3D Cu ULD, Xencos SA, Sassenage, France). The wavelength of the $X$-ray radiation is $0.154 \mathrm{~nm}$.

\section{Results and Discussion}

\subsection{Structure Characterization of the SR Resins}

The simplified hydrolysis and condensation reactions of TEOS and MTMS were shown in Scheme 1. The structure of $Q_{0}, Q_{1}, Q_{2}, Q_{3}, Q_{4}, T_{0}, T_{1}, T_{2}, T_{3}$ for silicon resins were also displayed in Scheme 1 [33,34]. Figure 2 shows the liquid-state ${ }^{29} \mathrm{Si}$ NMR result of silicon resins. It revealed that the structure of the oligomer was formed, while the existence of $T_{0}, T_{1}, T_{2}, Q_{0}, Q_{1}, Q_{2}, Q_{3}$ indicated that the condensation reaction between MTMS and TEOS was incomplete. With the amount of ethanol decreasing, the signals of $T_{2}, T_{3}$ and $Q_{2}, Q_{3}$ became stronger, which illuminated that ethanol dosage can inhibit the condensation reaction of siloxane. The effect of the ethanol can be concluded in two aspects. On the one hand, ethanol diluted the concentration of reactants; on the other hand, ethanol, as a product of hydrolysis reaction, can inhibit the hydrolysis reaction [33]. Thus, the polycondensation reaction slowed down, which led to a lower degree of condensation. As the GPC result shown in Figure 3, with the amount of ethanol decreasing, the number of average molecular weight $\left(M_{n}\right)$ and weight-average molar weight $\left(M_{\mathrm{W}}\right)$ of SR samples increased; and the polymer dispersity index (PDI) also increased. It indicated that ethanol worked as an inhibitor for the polycondensation reaction. A higher ethanol amount resulted in a lower condensation degree, and more $\mathrm{Si}-\mathrm{OH}$ groups were expected to be left.

FTIR was used to characterize the structure of SR, and the spectra are shown in Figure 4. Signals at $1272 \mathrm{~cm}^{-1}$ and $778 \mathrm{~cm}^{-1}$ were assigned to $\mathrm{Si}-\mathrm{CH}_{3}$, which will not join reactions and can be used as an internal reference. The broad absorption band appearing at $3000-3600 \mathrm{~cm}^{-1}$ was attributed to the stretching vibration of $-\mathrm{OH}$ in silanol groups $(\mathrm{Si}-\mathrm{OH})$ and alcoholic hydroxyl groups. Peaks at around $907 \mathrm{~cm}^{-1}$ and $1066 \mathrm{~cm}^{-1}$ were ascribed to stretching vibration of Si-O in silanol groups and $\mathrm{Si}-\mathrm{O}-\mathrm{Si}$ groups. The amount of residual Si-O- $\mathrm{CH}_{2}-\mathrm{CH}_{3}$ and $\mathrm{Si}-\mathrm{O}-\mathrm{CH}_{3}$ in $\mathrm{SRs}$ are characterized by NMR (Figure S1), and it was indicated that most of Si-O-R were hydrolyzed to $\mathrm{Si}-\mathrm{OH}$. With the amount of ethanol increased, the intensity of the $\mathrm{Si}-\mathrm{OH}$ peaks increased, while that of the $\mathrm{Si}-\mathrm{O}-\mathrm{Si}$ signals decreased and blue-shifted. It revealed that the hydrolysis and condensation reaction of $\mathrm{Si}-\mathrm{O}-\mathrm{CH}_{3} / \mathrm{C}_{2} \mathrm{H}_{5}$ in MTMS and TEOS has occurred, and the higher amount of ethanol added, the lower 
degree of condensation and the higher content of silanol groups was obtained. Chemical structure of silicon resins can be changed by modulation of hydrolysis and condensation reaction of siloxane.<smiles>CO[Si](C)(O)O[14CH2][14CH2][14CH2]O[Si](C)(O)O</smiles><smiles>CO[Si](OC)(OC)OCCCCCCO</smiles>

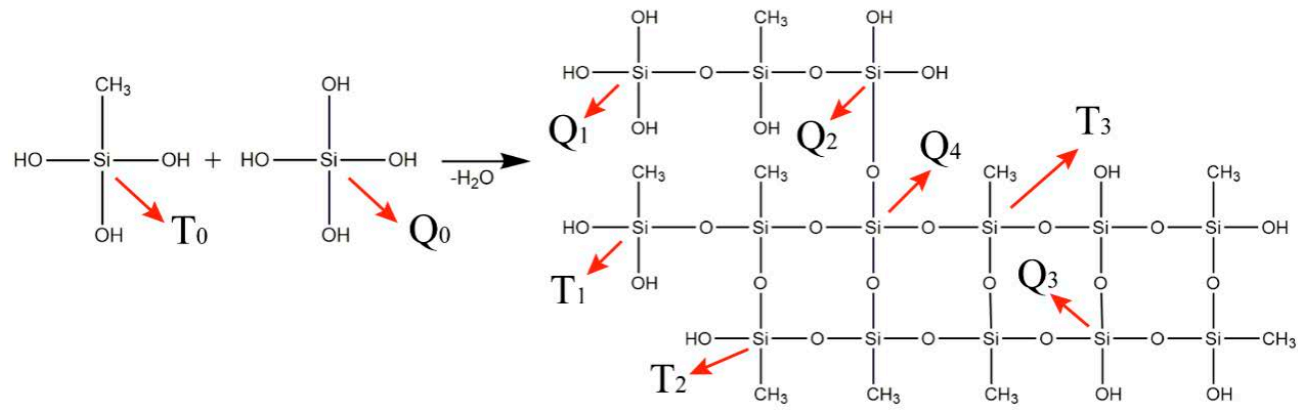

Scheme 1. The hydrolysis and condensation reactions of TEOS and MTMS.

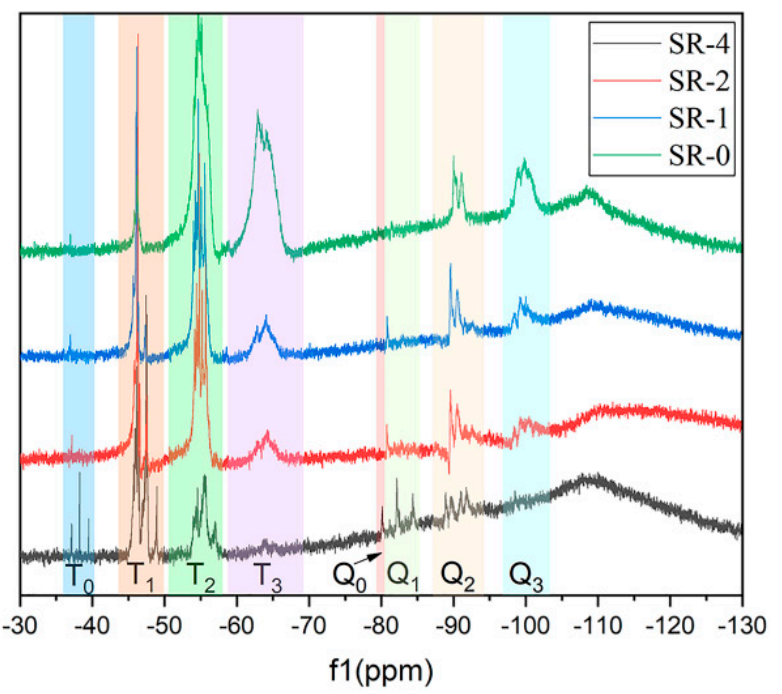

Figure $2 .{ }^{29} \mathrm{Si}$ NMR of the silicon resins.

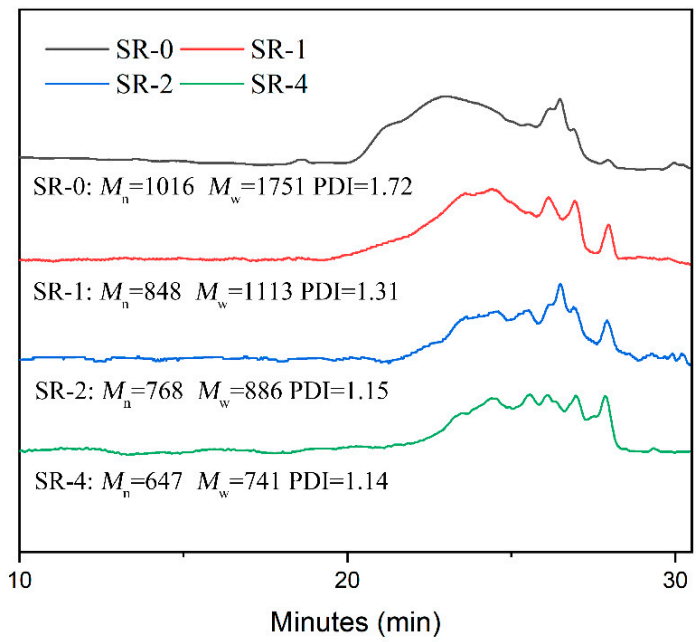

Figure 3. GPC spectra of silicon resins. 


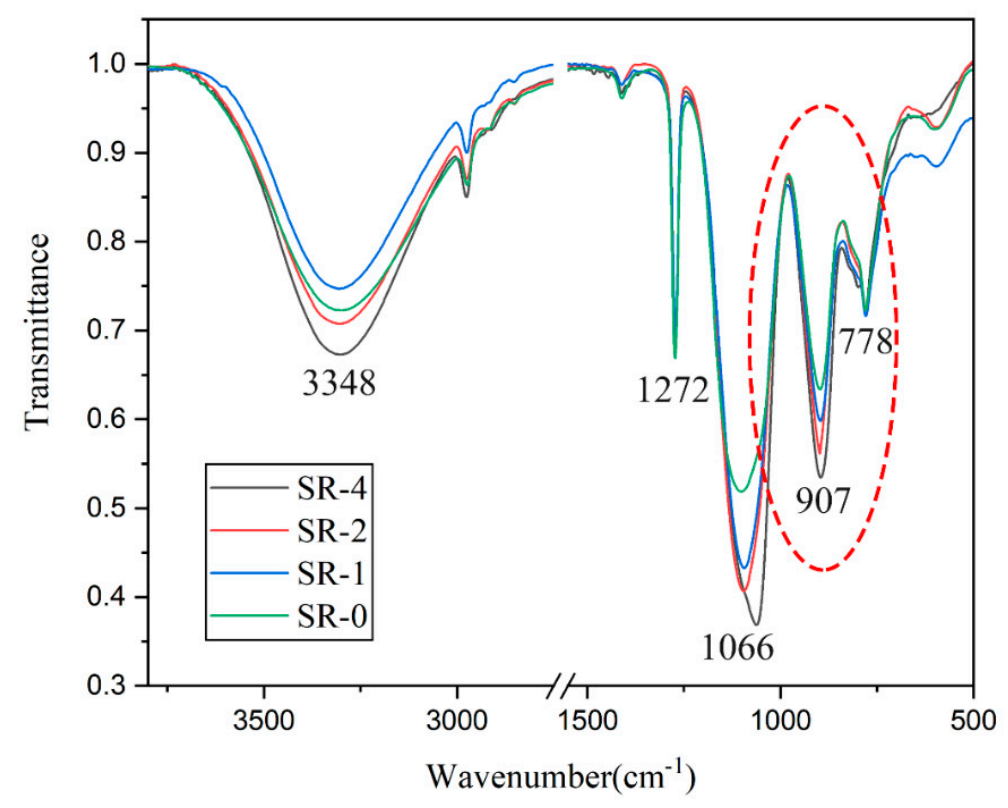

Figure 4. FTIR spectra of the silicon resins.

\subsection{Curing Process of SPF Hybrid Resin}

The SPF hybrid resin was prepared by mixing the solution of PF and SR in a weight ratio of 1:1. In order to investigate the curing reaction of hybrid resins, SPF-4 resins with different curing degrees were selected to carry out the characterization of the chemical group through FTIR spectroscopy (shown in Figure 5). Peaks at $1660 \mathrm{~cm}^{-1}, 1605 \mathrm{~cm}^{-1}$ and $1479 \mathrm{~cm}^{-1}$ corresponded to the characteristic peaks of phenolic resins. As the curing reaction proceeds, the intensity of the absorption band attributed to Si-OH at $907 \mathrm{~cm}^{-1}$ decreased, and a shoulder peak at $945 \mathrm{~cm}^{-1}$ attributed to Si-O-Ph appeared and became stronger, indicating the condensation reaction of silicon resins and the reaction between $\mathrm{Si}-\mathrm{OH}$ and $\mathrm{Ph}-\mathrm{OH}$ occurrence throughout the curing process.

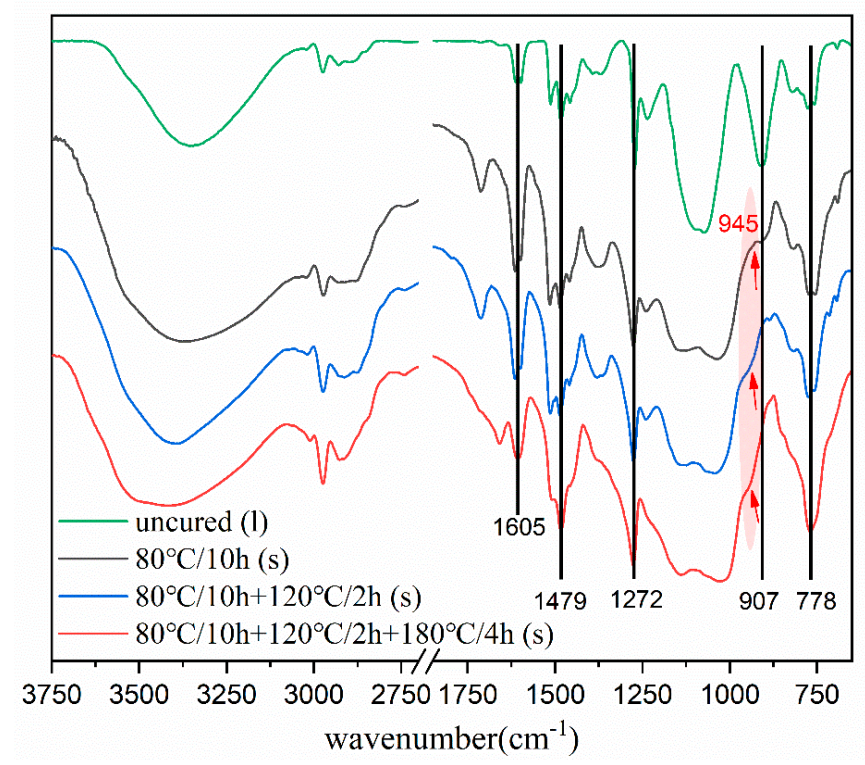

Figure 5. FTIR spectra for SPF-4 at different curing stages.

To study the chemical reactions in the early curing process, the chemical structure of SPF-4 resins cured at $80^{\circ} \mathrm{C}$ for $2 \mathrm{~h}$ was analyzed through FD-MS, and the results are shown in Figure 6 . Ion fragment signals at $94 \mathrm{~m} / \mathrm{z}, 124 \mathrm{~m} / \mathrm{z}, 154 \mathrm{~m} / \mathrm{z}, 290 \mathrm{~m} / \mathrm{z}$, etc., were characteristic peaks of phenolic resins and the 
chemical structures of other strong signals are listed next to the spectrum [35]. Ion fragment peaks at $200 \mathrm{~m} / \mathrm{z}, 230 \mathrm{~m} / \mathrm{z}, 244 \mathrm{~m} / \mathrm{z}, 260 \mathrm{~m} / \mathrm{z}, 276 \mathrm{~m} / \mathrm{z}$ and $304 \mathrm{~m} / \mathrm{z}$ indicated that Si-OH had reacted with Ph-OH to generate $\mathrm{Si}-\mathrm{O}-\mathrm{Ph}$ in the early $80^{\circ} \mathrm{C}$ curing step before the SPF-4 resin gelled.

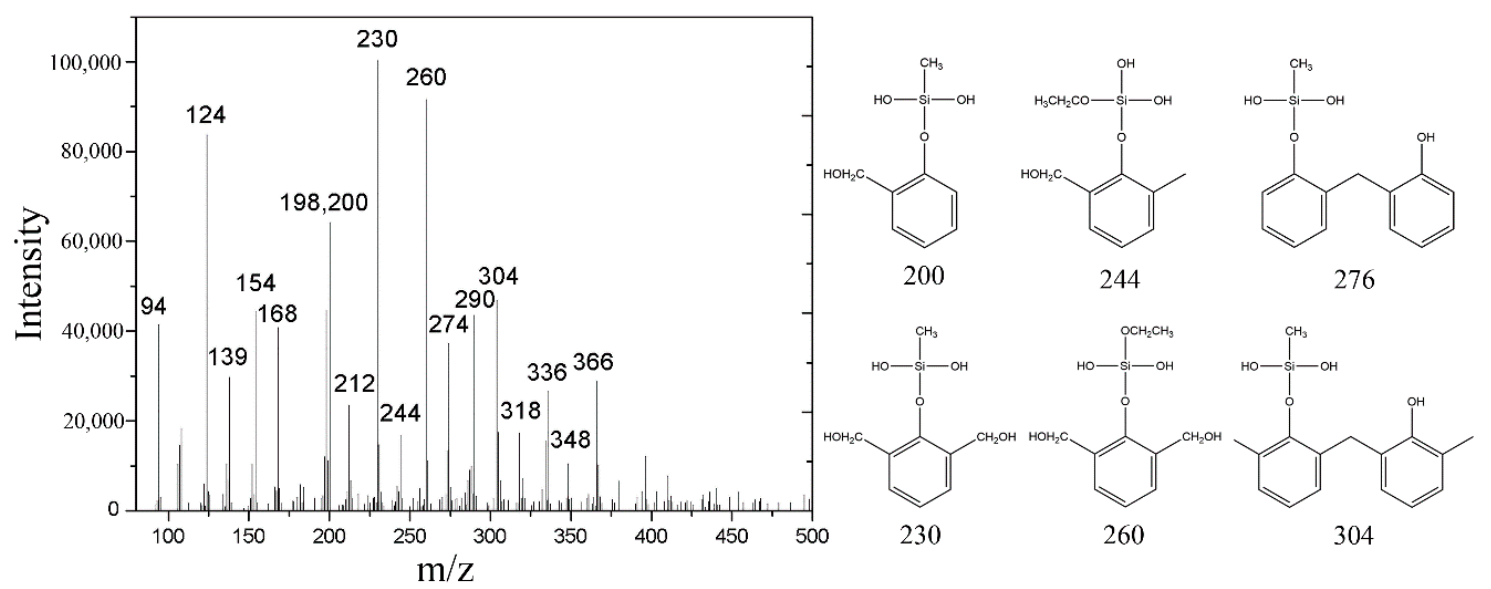

Figure 6. FD-MS spectra of the SPF-4 hybrid resins cured at $80^{\circ} \mathrm{C}$ for $2 \mathrm{~h}$ and the corresponding chemical structure.

The degree of reaction of $\mathrm{Si}-\mathrm{OH}$ and $\mathrm{Ph}-\mathrm{OH}$ varied between the cured SPF samples $\left(80{ }^{\circ} \mathrm{C} / 10 \mathrm{~h}+\right.$ $120^{\circ} \mathrm{C} / 2 \mathrm{~h}+180^{\circ} \mathrm{C} / 4 \mathrm{~h}$ ). As shown in Figure 7, with the content of Si-OH in silicon resins increasing, the intensity of the peak at $945 \mathrm{~cm}^{-1}$ attributed to $\mathrm{Si}-\mathrm{O}-\mathrm{Ph}$ became stronger, which illustrated that the higher Si-OH content in SRs, the more reaction with Ph-OH. Thus, the cured SPF-4 had the most Si-O-Ph bonds.
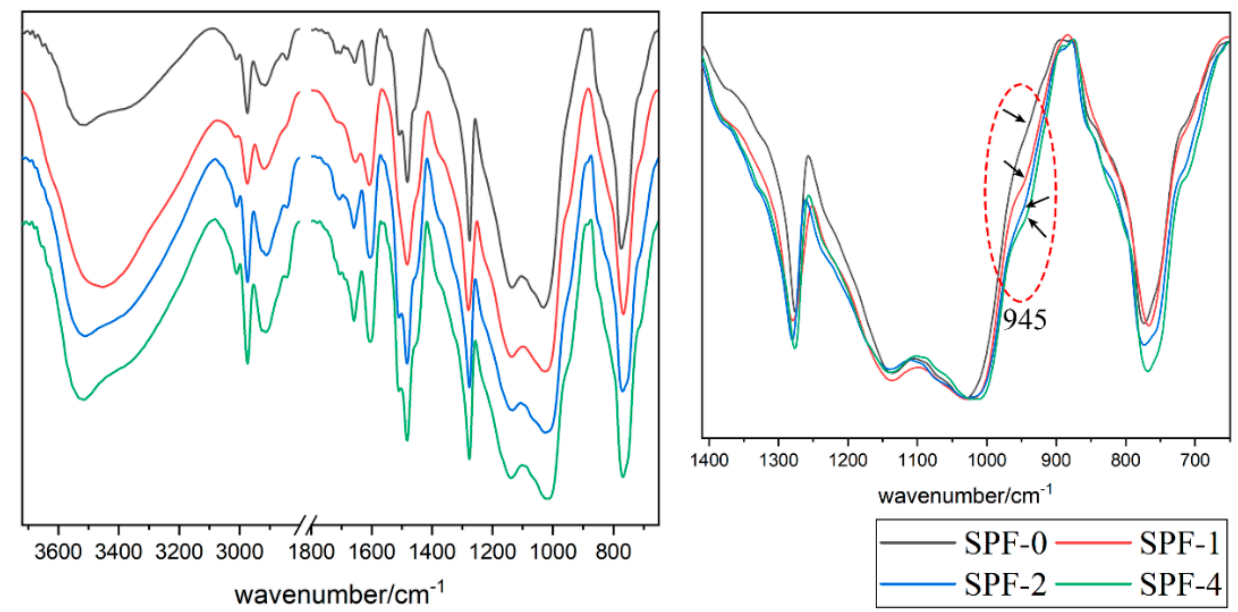

Figure 7. FTIR spectra and partially enlarged spectra of the cured SPF hybrid resins. The signal at $900 \sim 1000 \mathrm{~cm}^{-1}$ was shown on the right to clarify the difference.

\subsection{The Morphology of the Cured Hybrid Resins}

SEM was conducted to observe the fractured surface of the cured hybrid resins; the results are shown in Figure 8. Phase separation occurred and a homogeneous sea-island structure was formed for the cured SPF-0, SPF-1 and SPF-2 samples. The average size of the island phase gradually decreased, from 1 2 $\mu \mathrm{m}$ in SPF-0 to 0.5 1 $\mu \mathrm{m}$ in SPF-1 and 100 500 nm in SPF-2. No obvious phase separation in the submicron scale was observed in the SPF-4 sample. 

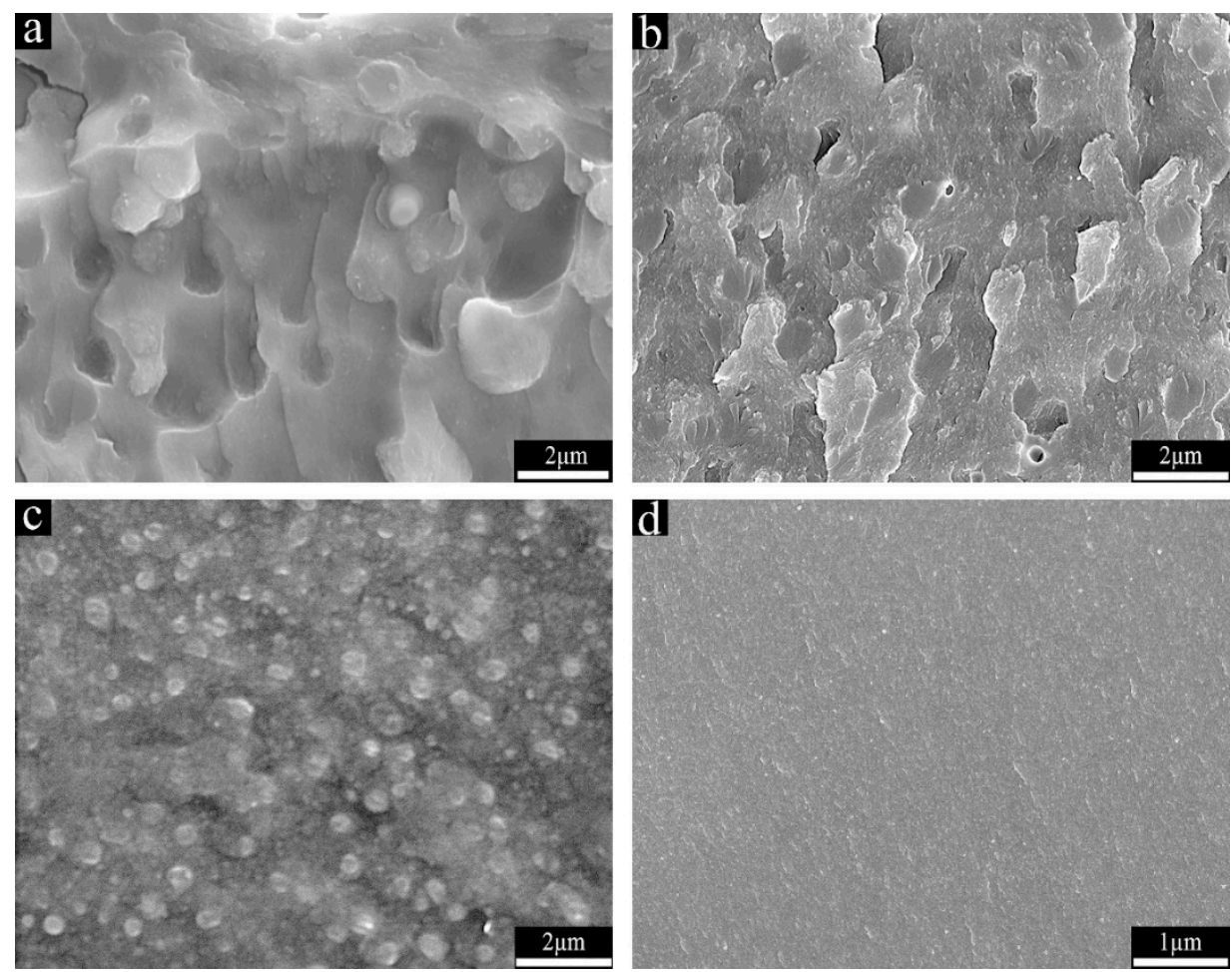

Figure 8. SEM images of the cured hybrid resins (a) SPF-0, (b) SPF-1, (c) SPF-2, (d) SPF-4.

In order to further detect the phase structure of SPF-4, small-angle X-ray scattering (SAXS) was used to detect thin film of the cured hybrid SPF-4 resins. Electron density contrast difference between phenolic resins and silicon resins [36] was detected and scattering intensity $(I)$ in the scattering vector range $(q)\left(0.01 \sim 0.14 \mathrm{~A}^{-1}\right)$ was obtained. $I q^{2}$, Lorentz-correction scattered intensity, can be used to analyze the degree of phase separation in the cured hybrid resins and highlight the position of the SAXS peak [37]. $I \sim q$ and $I q^{2} \sim q$ are plotted in Figure 9. The $q$ peak value was estimated to $0.045 \mathrm{~A}^{-1}$, which corresponded to a phase domain length for the cured SPF- 4 of $L=\frac{2 \pi}{q}=14 \mathrm{~nm}$.

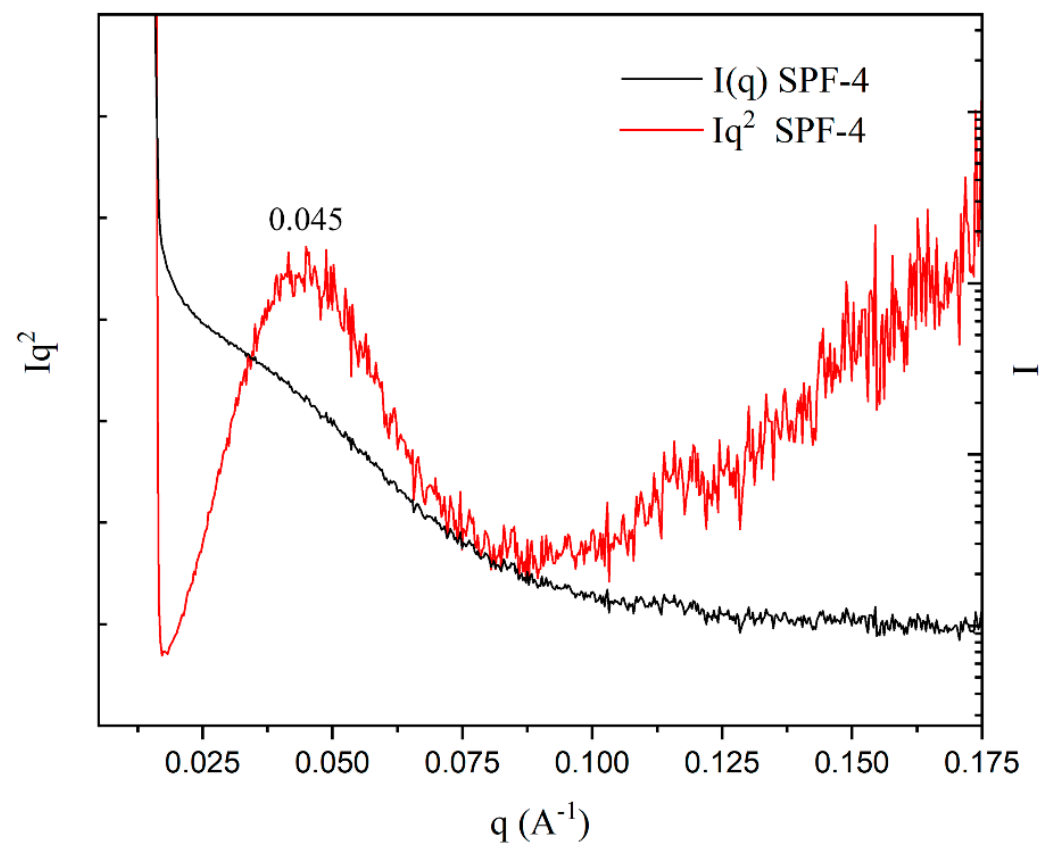

Figure 9. SAXS data for the cured SPF-4 resins. 
The nanoscale phase separation structure of the cured SPF-4 sample can be confirmed by HF-etched and oxidization-etched, respectively. As shown in Figure 10, after the sample was etched in HF solution for $24 \mathrm{~h}$, the silicon component near the fractured surface was almost totally removed (as shown in the EDS comparison before and after HF-etching). No phase separation in the micro-scale was observed in the fractured surface of SPF-4. After the HF-etching treatment, a relatively sharp interface can be observed in the remained structure with connected domains in about twenty nanometers, which was close to domain scales in the homogeneous resins [38], as was consistent with the SAXS result and indicated the excellent compatibility between silicon and phenolic resins. After the cured resins were oxidized at $700{ }^{\circ} \mathrm{C}$ for $2 \mathrm{~h}$ in a muffle furnace; the results are shown in Figure 11, phenolic resins were pyrolyzed to form pores and the silicon resins changed to silica and remained. The in-situ constructed silica phase showed similar images as the HF-etched case. By measuring Figure 11b, the size of the silica phase was about 7 15 nm. After collecting samples of the oxidized hybrid resins, BET measurement was conducted and pore size of approximately $7 \mathrm{~nm}$ was obtained. According to the above analysis, the phase domain length scale of SPF-4 was about 7 15 nm. Comparing with various reported silicon modified phenolic resins (Figure 1), the cured SPF-4 hybrid resins had the lowest phase domain length and the highest silicon content. Because of the uniform component distribution and nanoscale phase structure formation, relatively compact silica film was formed at the surface when the hybrid material was in the ablation atmosphere, as will be shown in the following context.
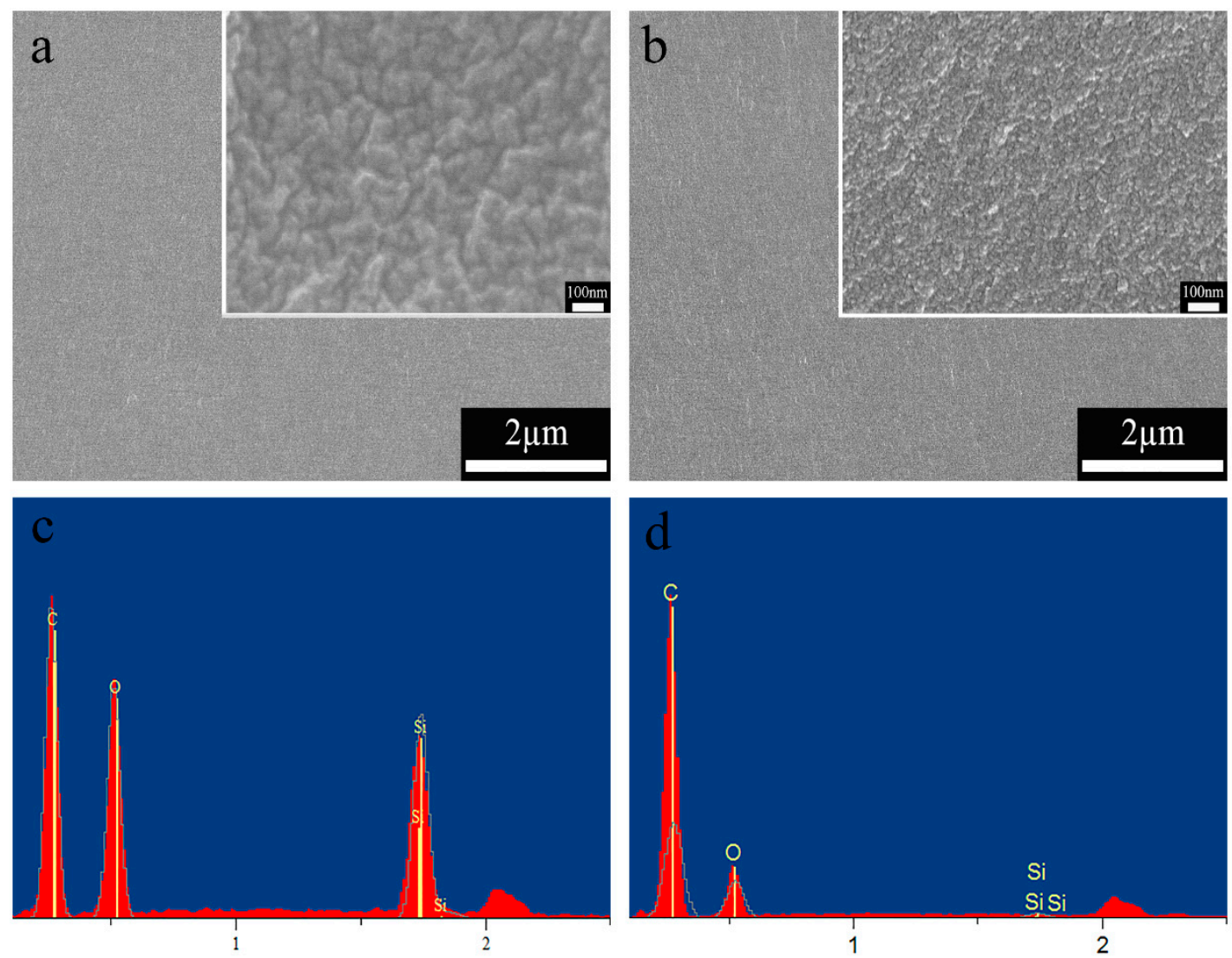

Figure 10. SEM images of the fractured surface of SPF-4 before (a) and after HF-etching (b). Higher magnified images were inserted, respectively. The EDX result is correspondingly shown below in (c) and (d). 

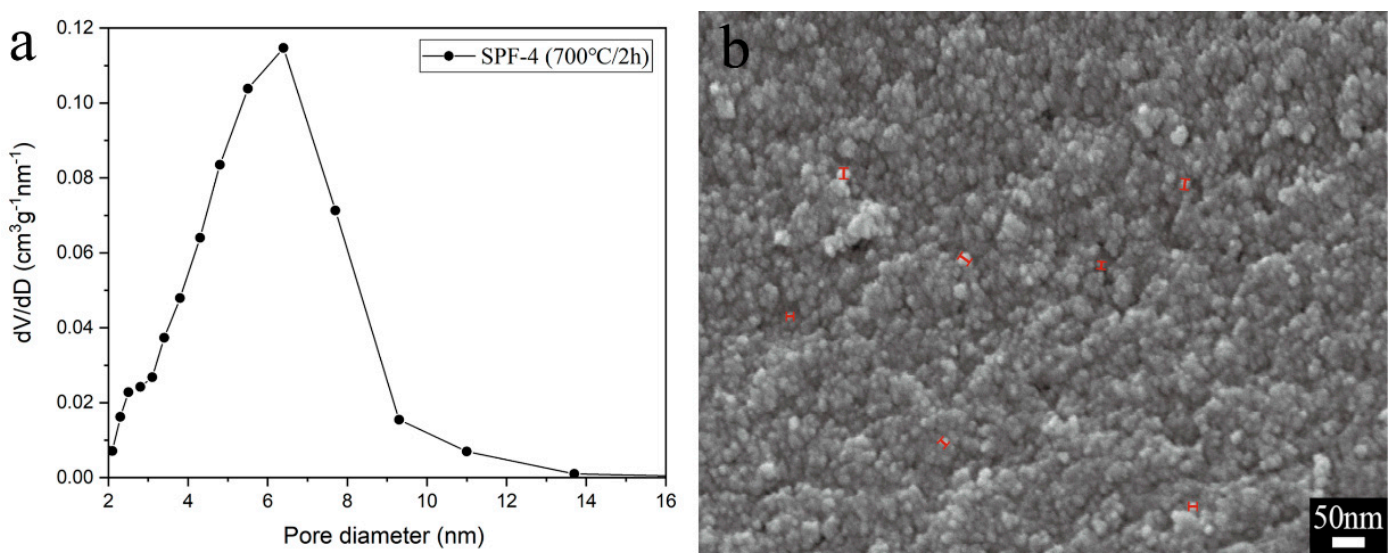

Figure 11. BJH (Barrett-Joyner-Halenda) pore size distribution plots (a) and SEM image (b) of the cured SPF-4 resins oxidized for $2 \mathrm{~h}$ at $700{ }^{\circ} \mathrm{C}$.

The phase structure formation process was schematically shown in Figure 12, where SPF-4 and SPF-0 were given in contrast. More silanol groups remained and a lower degree of condensation for silicon resin increase the possibility of silanol groups reacting with phenolic hydroxyl, which resulted in more $\mathrm{Si}-\mathrm{O}-\mathrm{Ph}$ bonds being formed in the cured SPF-4 hybrid resins. Increasing $\mathrm{Si}-\mathrm{O}-\mathrm{Ph}$ formation can improve compatibility between silicon resin and phenolic resin, which can result in nanoscale phase separation rather than macroscopic phase separation. Therefore, the number of silanol groups in the SRs increased, and the length ofphase structure decreased.

\section{SPF-4}
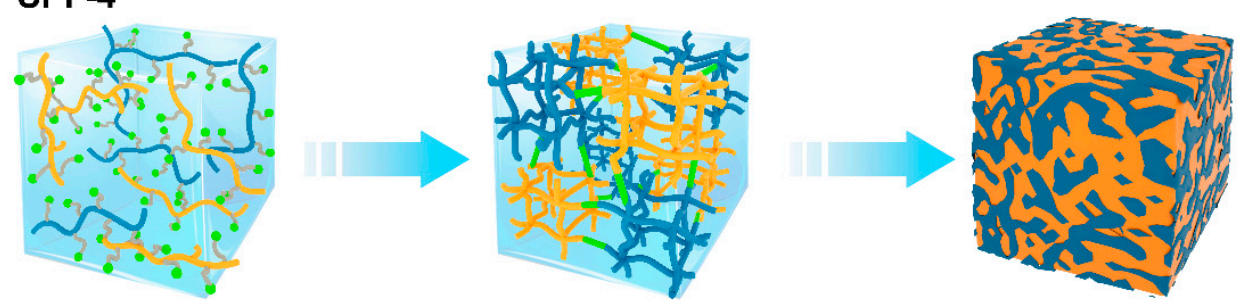

\section{SPF-0}
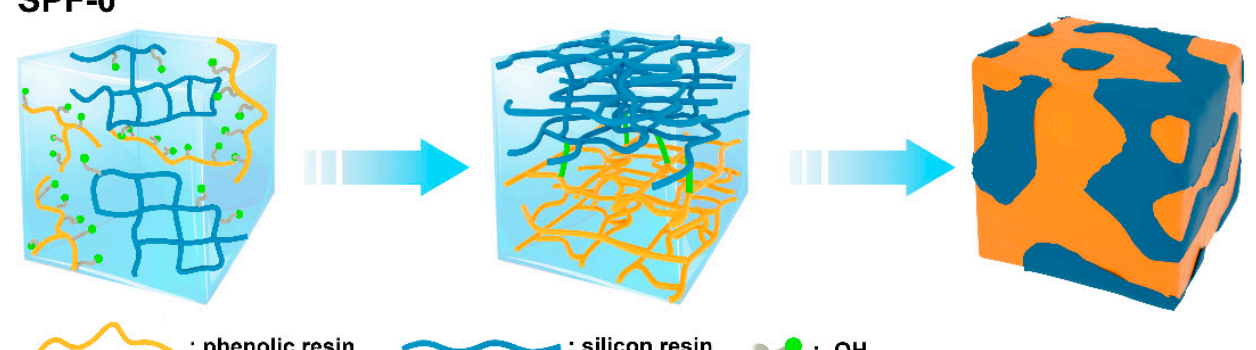

Figure 12. Schematic of the phase separation mechanism of SPF resins during curing.

\subsection{Thermal Stability of the SPF Resins}

TGA measurements were applied to evaluate the thermal properties of the cured SPF resins with different phase structures, and the corresponding data is shown in Table 1 . In $\mathrm{N}_{2}$ atmosphere (shown in Figure 13a), the initial thermal degradation temperature $\left(\mathrm{T}_{5 \%}\right)$ of the cured SPF-4 increased from $254.7^{\circ} \mathrm{C}$ (that of PF) to $405.3^{\circ} \mathrm{C}$. The residual weight of SPF- 4 was $74.52 \%$, which was the highest residual weight of all samples. With the decrease of the phase separation scale, the thermal stability of the cured hybrid resin improved. TGA results in air condition showed the same tendency (shown in Figure 13b). Compared to PF, the reaction of silanol groups and phenolic hydroxyl groups helped to reduce phenolic hydroxyl groups in SPF, which also contributed to decrease the possibility of being 
attacked by free radicals during pyrolysis and obtain higher thermal stability. In addition, as reported, the phase structure of resin has a great influence on thermal stability, and nanoscale phase separation helped to form a compact protective layer at high temperature [22]. As a consequence, the cured SPF-4 with most $\mathrm{Si}-\mathrm{O}-\mathrm{Ph}$ bonds and nanoscale phase separation had the best thermal stability.

Table 1. TGA results for cured PF and SPF.

\begin{tabular}{lcccc}
\hline \multirow{2}{*}{ Sample } & \multicolumn{2}{c}{$\mathbf{N}_{\mathbf{2}}$} & \multicolumn{2}{c}{ Air } \\
\cline { 2 - 5 } & $\left.\mathbf{T}_{\mathbf{5 \%}}{ }^{\mathbf{a}}{ }^{(} \mathbf{C}\right)$ & $\mathbf{R}_{\mathbf{m a x}}{ }^{\mathbf{b}} \mathbf{( \% )}$ & $\left.\mathbf{T}_{\mathbf{5} \%}{ }^{\mathbf{a}}{ }^{\circ} \mathbf{C}\right)$ & $\mathbf{R}_{\mathbf{m a x}}{ }^{\mathbf{b}} \mathbf{( \% )}$ \\
\hline PF & 254.7 & 59.7 & 291.6 & 0.0 \\
SPF-0 & 285.5 & 71.9 & 337.0 & 32.8 \\
SPF-1 & 353.1 & 73.1 & 386.2 & 33.7 \\
SPF-2 & 386.8 & 73.9 & 397.3 & 37.4 \\
SPF-4 & 405.3 & 74.5 & 401.3 & 38.0 \\
\hline Thermal decomposition temperature at $5 \%$ weight loss. ${ }^{\mathbf{b}}$ Residual weight at $100{ }^{\circ} \mathrm{C}$.
\end{tabular}

a

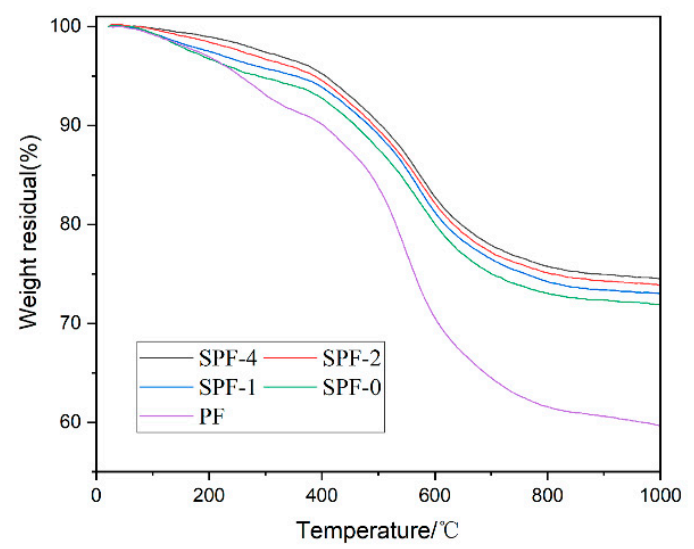

$\mathrm{b}$

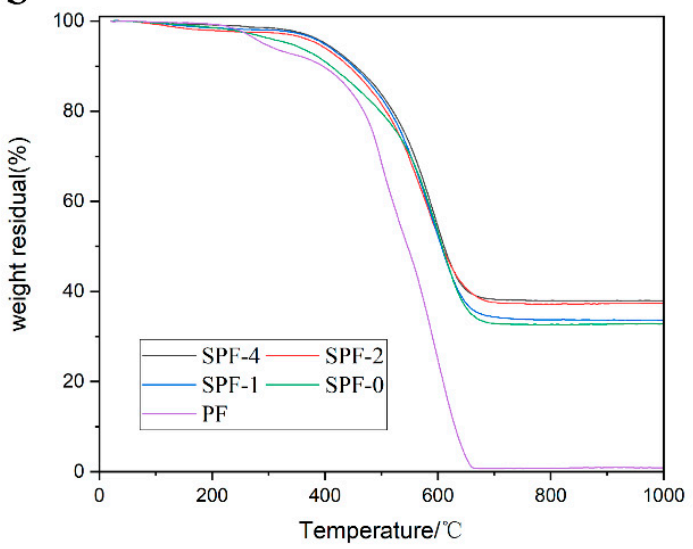

Figure 13. TGA curves of cured PF and SPF resins: (a) in $\mathrm{N}_{2}$ atmosphere and (b) in the air atmosphere.

A high-temperature oxidation test was conducted in a muffle furnace to investigate the weightresidual of the hybrids with different oxidation time at $1000{ }^{\circ} \mathrm{C}$, as shown in Figure 14. For the sake of comparison, grinded powders were used for this oxidation experiment. SPF samples showed higher residual weight than pure PF at different oxidation times. All the SPF samples became white when they were oxidized for $120 \mathrm{~min}$, as indicated that phenolic resin was completely decomposed with almost the same weight of $\mathrm{SiO}_{2}$ (about 33.5\%) left, which was consistent with the same amount of silicon source used as a design. At an oxidation time of $30 \mathrm{~min}$, only $30 \%$ weight of pure PF was left, while $53 \%$ of SPF- 0 and $57 \%$ of SPF-4 were left. At $60 \mathrm{~min}$, the residual weight of PF was nearly zero, while the residual weight ratios of SPF- 0 and SPF- 4 were about $41 \%$ and $44 \%$, respectively. Compared to $33 \%$ after $120 \mathrm{~min}$, it indicated that phenolic resin remained in the cured SPF samples. It showed that the silicon source helped to improve the oxidation resistance of PF resin. The cured SPF-4 had the highest residual weight, which was in good consistency with the TGA results. With the same amount of silicon source used, the microstructure of the SPF samples played a key role in their thermal oxidation resistance. The more ethanol used at the SR sample preparation period, the more $\mathrm{Si}-\mathrm{OH}$ remained, which resulted in more $\mathrm{Si}-\mathrm{O}-\mathrm{Ph}$ bonds to be generated and form nanoscale phase structure in the cured SPF samples. Fine phase structure with 7 15 nm size contributed to the excellent thermal oxidation stability of SPF-4 powders. 


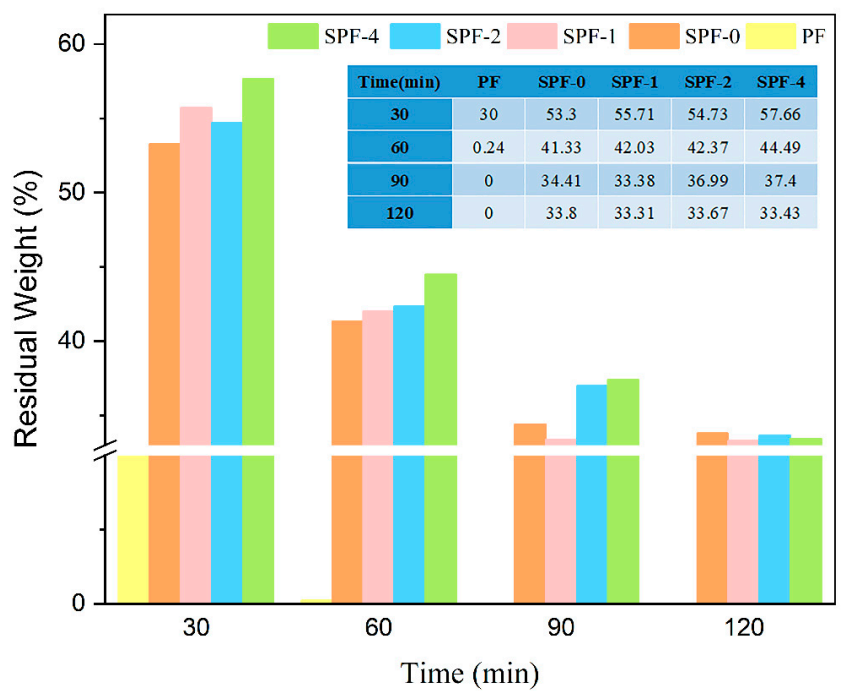

Figure 14. The weight retention of the cured SPFs after oxidation at $1000{ }^{\circ} \mathrm{C}$ for a different time in a muffle furnace.

To further prove this point, the surface of the oxidized SPF oxidized at $1000{ }^{\circ} \mathrm{C}$ for $1.2 \mathrm{~h}$ in a muffle furnace was observed with SEM, as shown in Figure 15. Numerous holes with a diameter of $1 \sim 2 \mu \mathrm{m}$ distributed in the surface of the cured SPF-0; and loose domains can be found inside. Holes were smaller in SPF-1 and SPF-2, being 0.5 1 $\mu \mathrm{m}$ and 100 500 nm, respectively. At the same time, the surface of the cured SPF-4 was compact without obvious holes. This result was consistent with the morphology of the cured hybrid resins (Figure 8). Large phase scaled samples led to large holes after the samples were oxidized for SPF-0, SPF-1 and SPF-2. For SPF-4, fine and dense nanoscale phase structure resulted in a compact Si-rich surface layer, which prevented oxygen from entering the interior and benefited to achieve the optimized oxidization performance.
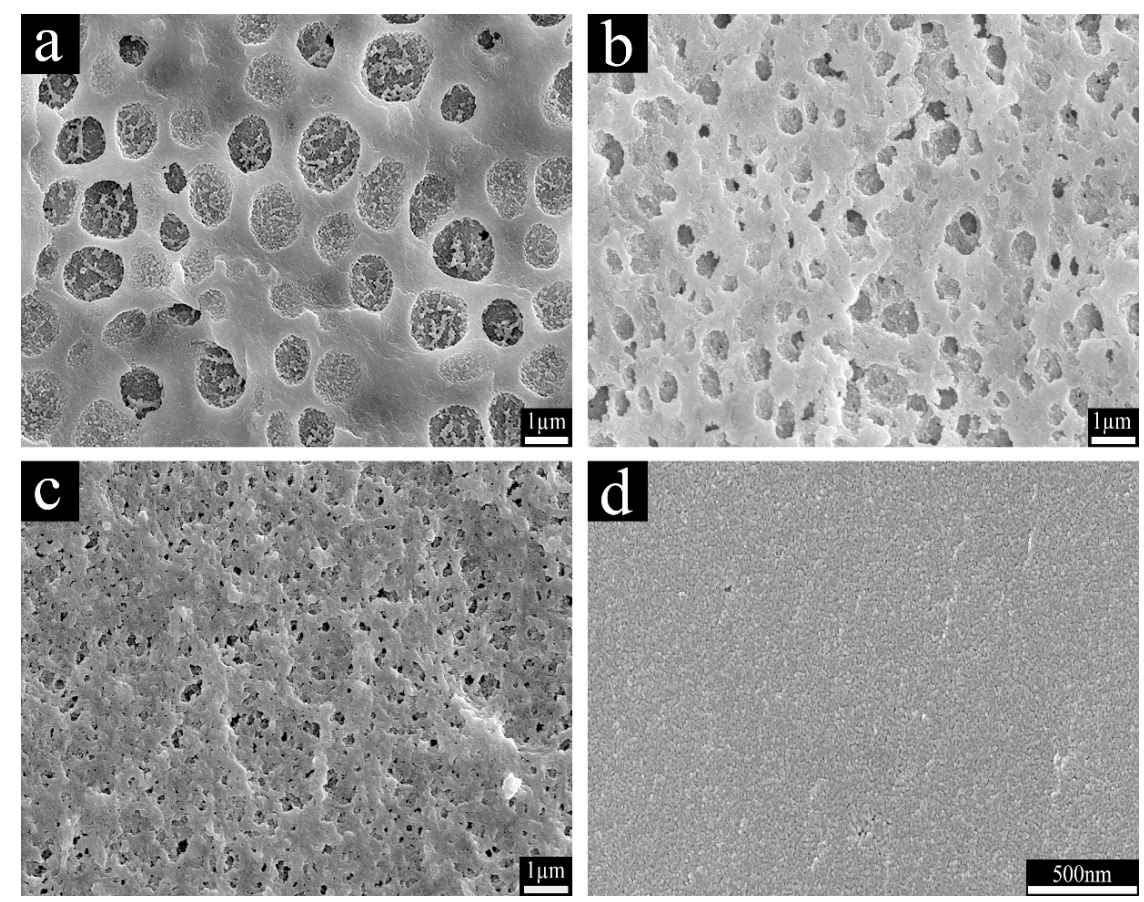

Figure 15. SEM images for the surface of the cured SPF resins after oxidation at $1000{ }^{\circ} \mathrm{C}$ for $1.2 \mathrm{~h}$, (a) SPF-0, (b) SPF-1, (c) SPF-2, (d) SPF-4. 
In order to further verify the better oxidation resistance of SPF-4 compared to PF, TG-IR was conducted to probe volatile products during degradation in air. The main volatile products were $\mathrm{CO}_{2}$ and $\mathrm{CO}$, and the low amount of the main degradation products meant the slow decomposition rate of the resins, reflecting good thermal stability. The intensity of absorption peak for volatilized $\mathrm{CO}_{2}$ and $\mathrm{CO}$ compounds versus time, as shown in Figure 16. The maximum absorption intensity of volatilized $\mathrm{CO}_{2}$ for PF was about 27.53, and that for SPF- 4 decreased to 10.59 . The variation tendency of volatilized $\mathrm{CO}$ was in keeping with volatilized $\mathrm{CO}_{2}$. It indicated that the amount of the main degradation products decreased and the thermal properties improved obviously via introducing silicon resins to phenolic resins, which can be attributed to the formation of a compact Si-rich layer and Si-O-Ph bond.
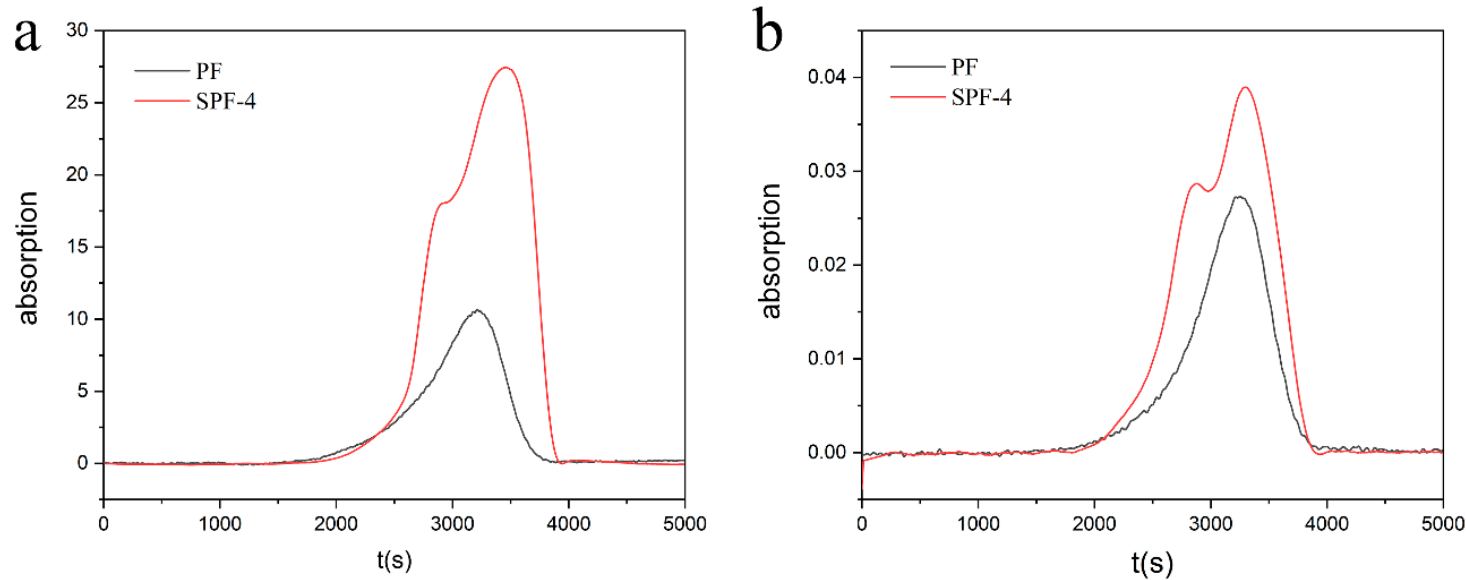

Figure 16. The intensity of the characteristic peak (a) $\mathrm{CO}_{2}$ and (b) $\mathrm{CO}$ in TG-IR spectra in air.

\subsection{Ablative Property and Flame Retardancy of the SPF Resins}

An oxyacetylene flame test was used to access the ablative property of SPF composite by calculating the mass ablation rate (MAR), which can assess the mass loss per second during ablation. A lower MAR means a lower erosion rate under the hot oxy-acetylene flame. The MAR decreased from $0.0723 \mathrm{~g} / \mathrm{s}$ (that of PF) to $0.0585 \mathrm{~g} / \mathrm{s}$ (that of SPF-4). It suggested that the ablative property of the composites was improved after the addition of silicon resins.

SEM was used to observe the morphology of materials before and after ablation. The interior morphologies of PF and SPF-4 composites without ablation were shown in Figure 17a,b. The combination of SPF-4 hybrid resin with high silica fiber was compacter than PF, because $\mathrm{Si}-\mathrm{OH}$ on the surface of the fiber can react easily with Si-OH of SPF-4 to improve the adhesive interface performance. However, the combination of PF resin and fiber resulted in large cracks, which benefited the erosion of oxygen and heat flow. The SEM morphologies of the ablated composites surface were shown in Figure 17c,d. It was found that a compact silicon dioxide protective layer was formed on SPF-4 composites after ablation. The SPF-4 resins and the fibers both contained silicon, which conduced to the rapid formation of silicon dioxide protective layer. As mentioned before, the nanoscale phase structure of SPF- 4 was easier to form a compact Si-rich layer. PF composites relied only on fibers to form a protective layer during ablation because phenolic resins were easy to be pyrolyzed at high temperature in air. Furthermore, the oxidation and decomposition of phenolic resin can cause holes on the surface of the composite material. To further proved this viewpoint, we analyzed the morphology and element content of the ablated composites through SEM (Figure 17e,f) and EDX (Table 2). For the ablated SPF-4 composites, the upper portion of the section (near the ablated surface) observed by SEM was compact without large holes, and the carbon content was reduced by $6.6 \%$ compared to that of the inner portion. However, the upper portion in the section of the ablated PF composites had many macropores, which prove that PF composites were easily eroded by oxygen and heat flow. The carbon content of the upper portion was reduced by $33 \%$ compared to the inside. As a result, it was found that introducing a silicon component and the rapid formation of a dense silica protective layer are the keys to improve the ablative property of the composite. 


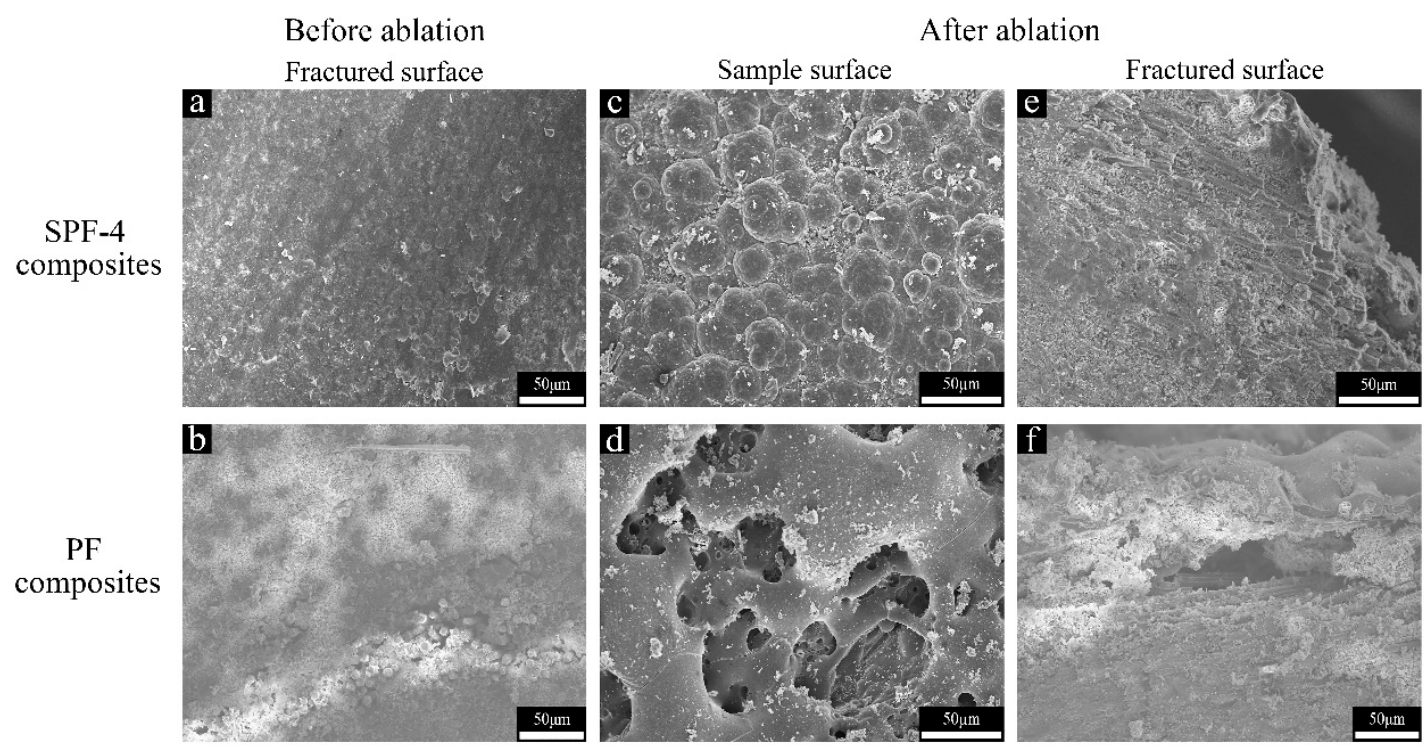

Figure 17. The SEM images for SPF-4 composites (a) and PF composites (b) before ablation; the SEM images for the surface of SPF-4 composites (c) and PF composites (d) after ablation; the SEM images for the fractured surface of SPF-4 composites (e) and PF composites (f) after ablation.

Table 2. The corresponding EDX results for the interior and the upper of SPF-4 composites and PF composites after ablation.

\begin{tabular}{ccccc}
\hline \multirow{2}{*}{ Element } & \multicolumn{2}{c}{ SPF-4 Composite } & \multicolumn{2}{c}{ PF Composite } \\
\cline { 2 - 5 } & Interior & Upper & Interior & Upper \\
\hline $\mathrm{C}$ & $20.30 \mathrm{wt} \%$ & $18.96 \mathrm{wt} \%$ & $43.19 \mathrm{wt} \%$ & $26.78 \mathrm{wt} \%$ \\
$\mathrm{O}$ & $42.10 \mathrm{wt} \%$ & $43.93 \mathrm{wt} \%$ & $24.44 \mathrm{wt} \%$ & $39.06 \mathrm{wt} \%$ \\
$\mathrm{Si}$ & $37.60 \mathrm{wt} \%$ & $37.11 \mathrm{wt} \%$ & $32.37 \mathrm{wt} \%$ & $34.16 \mathrm{wt} \%$ \\
\hline
\end{tabular}

The Cone Calorimeter (CC) test was conducted to evaluate the flammability of materials [39]. The pictures of SPF-4 and PF composites after the CC test were shown in Figure 18. The white surface of PF composites indicated that only high silica fibers remained after the test. However, the surface of SPF-4 composites after the test was rufous, suggesting that resins were still partially residual after the test. All parameter values for SPF-4 and PF were displayed in Table 3. HRR (heat release rate), PHRR (peak heat release rate), and THR (total heat release), important parameters to evaluate the fire safety, were decreased for SPF-4 owing to the introduction of silicon.
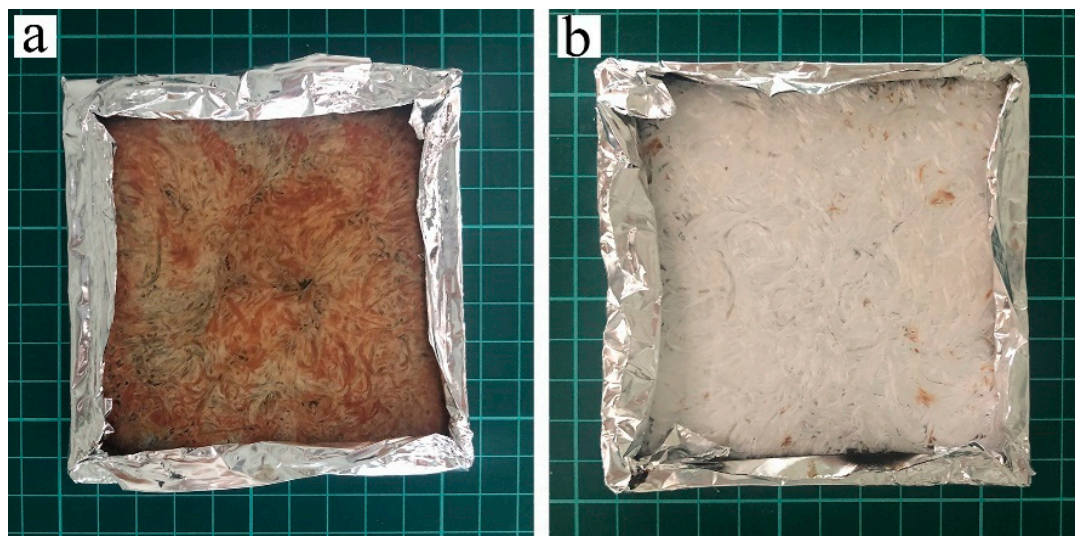

Figure 18. The picture of the (a) SPF-4 and (b) PF composites after the CC test. 
Table 3. Typical data from CC test for SPF and PF composites.

\begin{tabular}{lcc}
\hline & PF & SPF-4 \\
\hline PeakHRR $\left(\mathrm{kW} \cdot \mathrm{m}^{-2}\right)$ & 150.51 & 117.03 \\
MeanHRR $\left(\mathrm{kW} \cdot \mathrm{m}^{-2}\right)$ & 50.79 & 38.14 \\
THR $\left(\mathrm{MJ} \cdot \mathrm{m}^{-2}\right)$ & 21.86 & 17.57 \\
TSR $\left(\mathrm{m}^{2} / \mathrm{m}^{2}\right)$ & 199.48 & 146.66 \\
TOC $(\mathrm{g})$ & 14.28 & 11.40 \\
MeanMLR $(\mathrm{g} / \mathrm{s})$ & 0.020 & 0.013 \\
Residual $(\%)$ & 78.72 & 86.43 \\
\hline
\end{tabular}

Smoke suppression is another important aspect of flame retardancy [8]. The total smoke release (TSR) value of SPF-4 reduced $26.11 \%$ of PF. In addition, compared with PF, SPF-4 had comparatively lower total oxygen consumed (TOC), smaller mean mass loss rate (MeanMLR) and higher residual. These results demonstrated that SPF-4 acquired the improvement of flame retardancy. Owing to high Si-content and nanoscale phase structure, $\mathrm{SiO}_{2}$ and char residues can be quickly generated to cover the surface of the composites to form a dense and hard protective layer in the process of testing of SPF-4, preventing combustibles from entering the flame zone and oxygen from entering the inner layer of the polymer [33].

\section{Conclusions}

Silicon-modified phenolic resins (SPF) were prepared by simple mixing of silicon resins (SR) and phenolic resins (PF). Silicon resins with different degrees of condensation and content of silanol groups were obtained by adjusting the amount of ethanol added, which played an important role in regulating the morphology and properties of the hybrid resin. More silanol groups in the silicon resins can produce more Si-O-Ph bonds by the reaction between $\mathrm{Si}-\mathrm{OH}$ and $\mathrm{Ph}-\mathrm{OH}$. The formation of $\mathrm{Si}-\mathrm{O}-\mathrm{Ph}$ can enhance interfacial interaction and prevent phase separation during the curing process of SPF. Eventually, silicon-modified phenolic resins with nanoscale phase separation were obtained. Nanoscale phase separation and high Si-content endowed the cured hybrid resins with better thermal stability and oxidation resistance. The ablative property and flame resistance were also improved due to the introduction of silicon resins. Thus, hybrid resins can employed as potential composite matrix of ablative and fireproof materials.

Supplementary Materials: The following are available online at http://www.mdpi.com/2227-9717/8/9/1129/s1, Figure S1: Liquid-state 1H NMR spectra of SRs.

Author Contributions: Methodology, S.L. and H.L.; software, Y.D.; validation, H.L. and F.C.; investigation, Y.S.; resources, T.Z.; data curation, W.Y.; writing—original draft preparation, W.Y.; writing—review and editing, W.Y.; supervision, Z.L., H.L., T.Z. and F.C.; project administration, H.L.; funding acquisition, T.Z. All authors have read and agreed to the published version of the manuscript.

Funding: This research was funded by the National Natural Science Foundation of China (No. 51873215).

Acknowledgments: The authors gratefully acknowledge the financial support of the National Natural Science Foundation of China (No. 51873215).

Conflicts of Interest: The authors declare no conflict of interest.

\section{References}

1. Pilato, L. Phenolic resins: 100 years and still going strong. React. Funct. Polym. 2013, 73, 270-277. [CrossRef]

2. Shudo, Y.; Izumi, A.; Hagita, K.; Nakao, T.; Shibayama, M. Structure-mechanical property relationships in crosslinked phenolic resin investigated by molecular dynamics simulation. Polymer 2017, 116, 506-514. [CrossRef]

3. Wang, Y.; Wang, S.; Bian, C.; Zhong, Y.; Jing, X. Effect of chemical structure and cross-link density on the heat resistance of phenolic resin. Polym. Degrad. Stab. 2015, 111, 239-246. [CrossRef] 
4. Wang, S.; Jing, X.; Wang, Y.; Si, J. High char yield of aryl boron-containing phenolic resins: The effect of phenylboronic acid on the thermal stability and carbonization of phenolic resins. Polym. Degrad. Stab. 2014, 99, 1-11. [CrossRef]

5. Wang, S.; Xing, X.; Wang, Y.; Wang, W.; Jing, X. Influence of poly (dihydroxybiphenyl borate) on the curing behaviour and thermal pyrolysis mechanism of phenolic resin. Polym. Degrad. Stab. 2017, 144, 378-391.

6. Yun, J.; Chen, L.; Zhang, X.; Zhao, H.; Wen, Z.; Zhang, C. The effects of silicon and ferrocene on the char formation of modified novolac resin with high char yield. Polym. Degrad. Stab. 2017, 139, 97-106. [CrossRef]

7. Zhong, Y.; Jing, X.; Wang, S.; Jia, Q.-X. Behavior investigation of phenolic hydroxyl groups during the pyrolysis of cured phenolic resin via molecular dynamics simulation. Polym. Degrad. Stab. 2016, 125, 97-104. [CrossRef]

8. Li, S.; Chen, F.; Zhang, B.; Luo, Z.; Li, H.; Zhao, T. Structure and improved thermal stability of phenolic resin containing silicon and boron elements. Polym. Degrad. Stab. 2016, 133, 321-329. [CrossRef]

9. Yu, Z.L.; Yang, N.; Apostolopoulou-Kalkavoura, V.; Qin, B.; Ma, Z.Y.; Xing, W.Y.; Qiao, C.; Bergstrom, L.; Antonietti, M.; Yu, S.H. Fire-retardant and thermally insulating phenolic-silica aerogels. Angew. Chem. Int. Ed. Engl. 2018, 57, 4538-4542. [CrossRef]

10. Yun, J.; Chen, L.; Zhang, X.; Zhao, H.; Wen, Z.; Zhu, D. Synthesis and structure evolution of phenolic resin/silicone hybrid composites with improved thermal stability. J. Mater. Sci. 2018, 53, 14185-14203. [CrossRef]

11. Mercado, L.A.; Galia, M.; Reina, J.A. Silicon-containing flame retardant epoxy resins: Synthesis, characterization and properties. Polym. Degrad. Stab. 2006, 91, 2588-2594. [CrossRef]

12. Ahmad, S.; Gupta, A.P.; Sharmin, E.; Alam, M.; Pandey, S.K. Synthesis, characterization and development of high performance siloxane-modified epoxy paints. Prog. Org. Coat. 2005, 54, 248-255. [CrossRef]

13. Matsumoto, K.; Oba, Y.; Nakajima, Y.; Shimada, S.; Sato, K. One-pot sequence-controlled synthesis of oligosiloxanes. Angew. Chem. Int. Ed. Engl. 2018, 57, 4637-4641. [CrossRef] [PubMed]

14. Zhang, Y.M.; Huang, Y.; Liu, X.L.; Yu, Y.Z. Studies on the silicone resins cured with polymethylsilazanes at ambient temperature. J. Appl. Polym. Sci. 2003, 89, 1702-1707. [CrossRef]

15. Chen, Y.; Liu, L.; Zhan, M. The preparation and characterization of abrasion-resistant coatings on polycarbonate. J. Coat. Technol. Res. 2012, 10, 79-86. [CrossRef]

16. Haraguchi, K.; Usami, Y.; Yamamura, K.; Matsumoto, S. Morphological investigation of hybrid materials composed of phenolic resin and silica prepared by in situ polymerization. Polymer 1998, 39, 6243-6250. [CrossRef]

17. Yin, R.; Cheng, H.; Hong, C.; Zhang, X. Synthesis and characterization of novel phenolic resin/silicone hybrid aerogel composites with enhanced thermal, mechanical and ablative properties. Compos. Part. A Appl. Sci. Manuf. 2017, 101, 500-510. [CrossRef]

18. Humcke-Bogner, R.; Liu, J.-C.; Chien, Y.W. Methods for determining partial solubility parameters of potential film-coating polymers. Int. J. Pharm. 1988, 42, 199-209. [CrossRef]

19. Carraher, C.E., Jr. Carraher's Polymer Chemistry, 9th ed.; CRC Press: Boca Raton, FL, USA, 2013.

20. Li, S.; Han, Y.; Chen, F.; Luo, Z.; Li, H.; Zhao, T. The effect of structure on thermal stability and anti-oxidation mechanism of silicone modified phenolic resin. Polym. Degrad. Stab. 2016, 124, 68-76. [CrossRef]

21. Li, S.; Chen, F.; Han, Y.; Zhou, H.; Li, H.; Zhao, T. Enhanced compatibility and morphology evolution of the hybrids involving phenolic resin and silicone intermediate. Mater. Chem. Phys. 2015, 165, 25-33. [CrossRef]

22. Li, S.; Li, H.; Li, Z.; Zhou, H.; Guo, Y.; Chen, F.; Zhao, T. Polysiloxane modified phenolic resin with co-continuous structure. Polymer 2017, 120, 217-222. [CrossRef]

23. Liu, Y.; Zeng, K.; Zheng, S. Organic-inorganic hybrid nanocomposites involving novolac resin and polyhedral oligomeric silsesquioxane. React. Funct. Polym. 2007, 67, 627-635. [CrossRef]

24. Nguyen, B.N.; Meador, M.A.B.; Medoro, A.; Arendt, V.; Randall, J.; McCorkle, L.; Shonkwiler, B. Elastic behavior of methyltrimethoxysilane based aerogels reinforced with tri-isocyanate. ACS Appl. Mater. Interfaces 2010, 2, 1430-1443. [CrossRef] [PubMed]

25. Chiang, C.-L.; Ma, C.C.M. Synthesis, characterization, thermal properties and flame retardance of novel phenolic resin/silica nanocomposites. Polym. Degrad. Stab. 2004, 83, 207-214. [CrossRef]

26. Vallejo, P.P.; López, B.L.; Murillo, E.A. Hyperbranched phenolic-alkyd resins with high solid content. Prog. Org. Coat. 2015, 87, 213-221. [CrossRef] 
27. Xu, Y.; Chen, J.; Huang, J.; Cao, J.; Gérard, J.-F.; Dai, L. Nanostructure of reactive polyhedral oligomeric silsesquioxane-based block copolymer as modifier in an epoxy network. High. Perform. Polym. 2016, 29, 1148-1157. [CrossRef]

28. Zhao, B.; Xu, S.; Adeel, M.; Zheng, S. Formation of poss-poss interactions in polyurethanes: From synthesis, morphologies to shape memory properties of materials. Polymer 2019, 160, 82-92. [CrossRef]

29. Furukawa, N.; Yuasa, M.; Kimura, Y. Characterization of polysiloxane-block-polyimides with silicate group in the polysiloxane segments. Polymer 1999, 40, 1853-1862. [CrossRef]

30. Hu, D.; Zheng, S. Reaction-induced microphase separation in polybenzoxazine thermosets containing poly(N-vinyl pyrrolidone)-block-polystyrene diblock copolymer. Polymer 2010, 51, 6346-6354. [CrossRef]

31. Haraguchi, K.; Usami, Y. The novel organic-inorganic hybrid materials composed of phenolic resin and silica. Chem. Lett. 1997, 26, 51-52. [CrossRef]

32. Zhang, Y.; Lee, S.; Yoonessi, M.; Liang, K.; Pittman, C.U. Phenolic resin-trisilanolphenyl polyhedral oligomeric silsesquioxane (poss) hybrid nanocomposites: Structure and properties. Polymer 2006, 47, 2984-2996. [CrossRef]

33. Jia, P.; Liu, H.C.; Liu, Q.; Cai, X.F. Thermal degradation mechanism and flame retardancy of Mq silicone/epoxy resin composites. Polym. Degrad. Stab. 2016, 134, 144-150. [CrossRef]

34. Sakka, S.; Kamiya, K. The Sol-Gel transition in the hydrolysis of metal alkoxides in relation to the formation of glass fibers and films. J. Non-Cryst. Solids 1982, 48, 31-46. [CrossRef]

35. Wang, J.; Zhao, T. Field desorption mass spectrometry characterization for relative molecular mass and distribution of phenolic resin. Acta Polymerica Sinica 2012, 2, 103-110. [CrossRef]

36. Parnell, A.J.; Cadby, A.J.; Mykhaylyk, O.O.; Dunbar, A.D.; Hopkinson, P.E.; Donald, A.M.; Jones, R.A. Nanoscale phase separation of P3ht Pcbm thick films as measured by small-angle X-ray scattering. Macromolecules 2011, 44, 6503-6508. [CrossRef]

37. Ophir, Z.; Wilkes, G.L. Saxs analysis of a linear polyester and a linear polyether urethane-Interfacial thickness determination. J. Polym. Sci. Polym. Phys. Ed. 1980, 18, 1469-1480. [CrossRef]

38. Dušek, K. Are cured thermoset resins inhomogeneous? Angew. Makromol. Chem. 1996, 240, 1-15. [CrossRef]

39. Bonati, A.; Rainieri, S.; Bochicchio, G.; Tessadri, B.; Giuliani, F. Characterization of thermal properties and combustion behaviour of asphalt mixtures in the cone calorimeter. Fire Saf. J. 2015, 74, 25-31. [CrossRef]

(C) 2020 by the authors. Licensee MDPI, Basel, Switzerland. This article is an open access article distributed under the terms and conditions of the Creative Commons Attribution (CC BY) license (http://creativecommons.org/licenses/by/4.0/). 